\title{
The Corrosion Behavior of Carburized Aluminum Using DC Plasma
}

\section{Somayeh Pirizadhejrandoost, Mehdi Bakhshzad Mahmoudi, Elnaz Ahmadi, and Masoud Moradshahi}

\begin{abstract}
Applied Plasma Physics Lab., Plasma Physics \& Nuclear Fusion Research School, Nuclear Science \& Technology Research Institute, Tehran 14399-51113, Iran
\end{abstract}

Correspondence should be addressed to Masoud Moradshahi,mmoradshahi@aeoi.org.ir

Received 17 August 2011; Revised 3 November 2011; Accepted 20 December 2011

Academic Editor: Ludo Froyen

Copyright ( $) 2012$ Somayeh Pirizadhejrandoost et al. This is an open access article distributed under the Creative Commons Attribution License, which permits unrestricted use, distribution, and reproduction in any medium, provided the original work is properly cited.

\begin{abstract}
Because of the outstanding properties of aluminum, it is widely used in today's advanced technological world. However, its insufficient wear resistance limits its use for commercial and industrial applications. In this study, we performed DC diode plasma carburizing of aluminum in the gas composition of $\mathrm{CH}_{4}-\mathrm{H}_{2}(20-80 \%)$ and at a temperature of about $350^{\circ} \mathrm{C}$ for 4 and 8 hours. The corrosion properties of the untreated and plasma-carburized samples were evaluated using anodic polarization tests in $3 \mathrm{~N}$ $\mathrm{HCl}$ solution according to ASTM: G5-94. The metallurgical characteristics were then investigated using XRD and SEM. The results showed that the carburizing process improves the corrosion resistance of treated specimens at low temperature.
\end{abstract}

\section{Introduction}

Though aluminum is a thermodynamically reactive metal, it has an excellent corrosion resistance. This is due to the formation of a compact and adherent oxide film on the surface. Because of this, it is used in many applications such as buildings, power lines, transportation field, and food and chemical industry. The oxide film is passive in the $\mathrm{pH}$ rage of about 4 to 8.5 , but it easily dissolves in highly acidic or alkaline corrodents [1]. Moreover, it is not homogeneous and contains weak points at which localized corrosion may occur in environments containing halide ions such as seawater and offshore $[2,3]$. Hence, there are some restrictions in application of aluminum and its alloys in modern industries. The danger of localized carrion attack can be decreased by surface modification, which will decrease the number of possible localized attacks to minimum.

It has been shown that the surface properties of $\mathrm{Al}$ can be improved by the formation of a carbide surface layer $[4,5]$. The $\mathrm{Al}_{4} \mathrm{C}_{3}$ compound provides strength to the composite materials and alloys like $\mathrm{Al}-\mathrm{Al}_{4} \mathrm{C}_{3}, \mathrm{Al}-\mathrm{SiC}-\mathrm{Al}_{4} \mathrm{C}_{3}$, and $\mathrm{Al}-\mathrm{Al}_{3} \mathrm{Ti}^{-} \mathrm{Al}_{4} \mathrm{C}_{3}$ [6]. For this purpose, various processing technologies have been developed such as carburizing by plasma which takes place in a glow discharge region. In this process, the aluminum samples are bombarded by positive carbon ions. These ions penetrate into the surface of aluminum and form the $\mathrm{Al}_{4} \mathrm{C}_{3}$ compound which is resistant to chemical corrosion. Aluminum has low melting point of about $660^{\circ} \mathrm{C}$, and the carburized layer is formed in temperatures not more than $350^{\circ} \mathrm{C}$. Different methods have been used for the formation of a carbide layer such as ion implantation, carburizing in a plasma environment and in a plasma spot which is used for aluminum carburizing, using energetic carbon ions emitted from a low-energy $(1.5 \mathrm{~kJ})$ Mather type plasma focus device operated with methane [4].

\section{Experimental Procedure}

The experiment is carried out by using the DC diode plasma carburizing system. This apparatus has a cylindrical chamber with a height of about $80 \mathrm{~cm}$ and $30 \mathrm{~cm}$ in diameter with two steel electrodes (Figure 1).

A resistive heater under the cathode heats samples, and temperature is controlled through a thermocouple which 


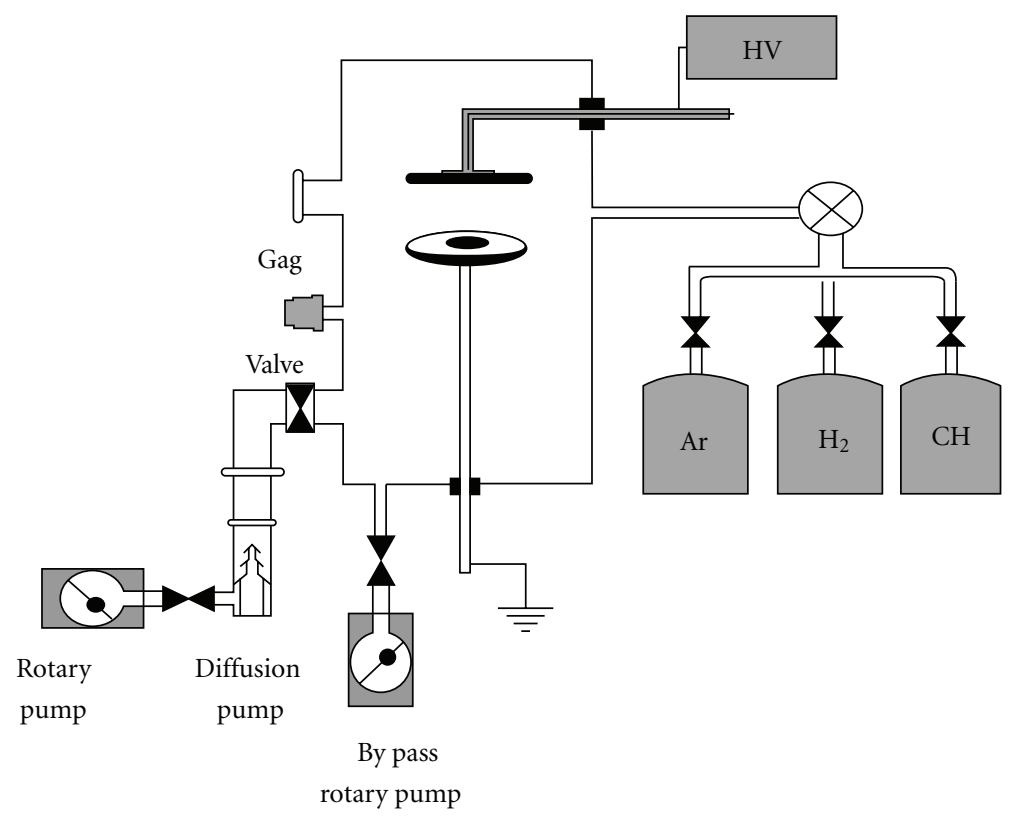

FIgURE 1: Schematic arrangement of the plasma discharge.

TABle 1: Chemical composition (wt.\%) of the main alloying elements in $\mathrm{Al} 1100$.

\begin{tabular}{ccccccccc}
\hline & $\mathrm{Si}$ & $\mathrm{Cu}$ & $\mathrm{Mn}$ & $\mathrm{Mg}$ & $\mathrm{Cr}$ & $\mathrm{Ti}$ & $\mathrm{Al}$ & $\mathrm{Fe}$ \\
\hline 1100 & 0.1 & 0.25 & 0.01 & 0 & 0 & 0.02 & $\mathrm{Rem}$ & 0.6 \\
\hline
\end{tabular}

is placed under the samples, by a temperature controller. The purity of applied gases including $\mathrm{H}_{2}, \mathrm{Ar}$, and $\mathrm{CH}_{4}$ was $99.99 \%$. Samples of pure aluminum (1100) were cut into $20 \times 20 \times 3 \mathrm{~mm}$, and then each of them was ground using $800,1000,1200$, and 2500-grit SiC paper carefully and then polished by using $1 \mu \mathrm{m} \mathrm{Al} \mathrm{Al}_{2} \mathrm{O}_{3}$ pastes before carburizing. Finally, the samples were cleaned by alcohol. The chemical composition of $\mathrm{Al} 1100$ is shown in Table 1.

Chemical composition (wt\%) of the main alloying elements in the $\mathrm{Al} 1100$ is determined by EDX. The pressure of sample chamber was reduced to $10^{-3} \mathrm{~Pa}$ by a rotary pump, and then by using a diffusion pump, the chamber evacuated to $10^{-5} \mathrm{~Pa}$. Because of the presence of aluminum oxide $\left(\mathrm{Al}_{2} \mathrm{O}_{3}\right)$ layer on the surface of every $\mathrm{Al}$ alloy that prevents the diffusing of carbon into the substrate, therefore, it is essential to remove the oxide layer by a treatment ioncleaning step called sputtering just before carburizing and to operate at low pressure [7]. Sputtering was performed in argon-hydrogen mixture with the total pressure of 0.12 torr, with the ratio of $30 \% \mathrm{H}_{2}$ and $70 \%$ Argon, and substrate temperature of $450^{\circ} \mathrm{C}$. The sputtering time was about 30 minutes. In this process, the argon ions accelerate toward the samples hit their surfaces and exchange their momentum with the oxide surface atoms. This condition was carried out for all experiments. Carburizing started immediately after $\mathrm{CH}_{4}$ and $\mathrm{H}_{2}$ mixture were injected into the chamber with the total pressure of about 2 torr. The ratio of the gases was the same in all experiments and was $20 \% \mathrm{CH}_{4}$ and $80 \% \mathrm{H}_{2}$. The
TABLE 2: Overview of the parameters used in the carburizing experiments.

\begin{tabular}{lccc}
\hline Sample No. Temperature $\left({ }^{\circ} \mathrm{C}\right)$ & Voltage $(\mathrm{V})$ & Treatment time $(\mathrm{h})$ \\
\hline 1 & 350 & 900 & 4 \\
2 & 310 & 700 & 4 \\
3 & 310 & 700 & 8 \\
\hline
\end{tabular}

applied voltage was varied in plasma carburizing between 700 and $900 \mathrm{v}$. All the condition is listed in Table 2.

The surfaces of specimens were prepared for metallographic interaction by SEM and for chemical corrosion tests. The $\mathrm{Al}_{4} \mathrm{C}_{3}$ phase was analyzed by XRD $\{$ (D8 advanced) with $\mathrm{Cu} \mathrm{K} \alpha$ radiation\}, and the weight percent of the surface elements was observed by EDX.

\section{Result and Discussion}

3.1. The Crystalline Phases. The X-ray diffraction was performed to identify $\mathrm{Al}_{4} \mathrm{C}_{3}$ phase in the experiment. The structure of the layer is Al-carbide; the XRD pattern is acquired at a grazing incident $0.3^{\circ}$ by operating the machine at $40 \mathrm{kV}$ and $30 \mathrm{~mA}$ by implying $\mathrm{Cu} \mathrm{K} \alpha$ radiation. The pattern of radiated samples is shown in Figure 2. The peaks corresponding to $\mathrm{Al}_{4} \mathrm{C}_{3}$ phases located at about $2 \theta \cong 38.53^{\circ}$, $2 \theta \cong 44.92^{\circ}$, and also $2 \theta \cong 65.34^{\circ}$.

The broadening of $\mathrm{Al}_{4} \mathrm{C}_{3}$ peak is an indication of the grain size of precipitates. This is obtained by using the Scherrer formula [8]

$$
d=\frac{k \lambda}{B \cos \theta},
$$

where $k$ is the Scherrer constant (0.99), $\lambda$ is the wavelength of $\mathrm{Cu} \mathrm{K} \alpha(=0.15 \mathrm{~nm}), B$ is the full width at half-maximum 


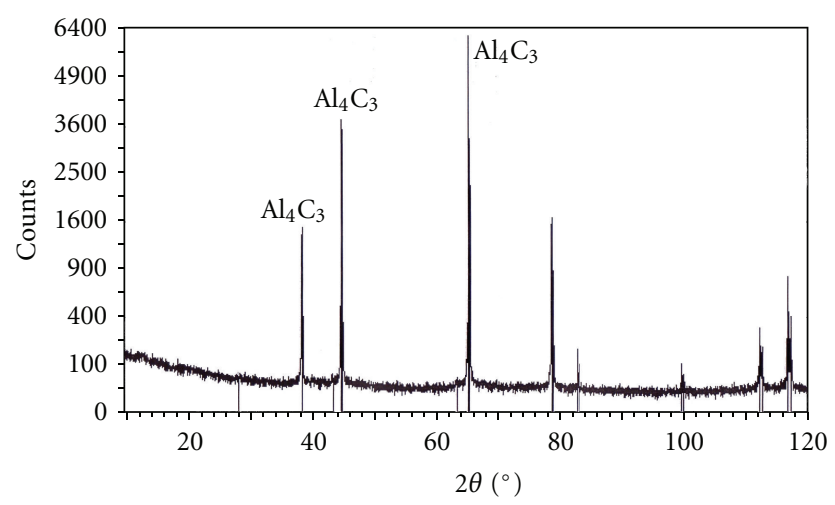

(a)

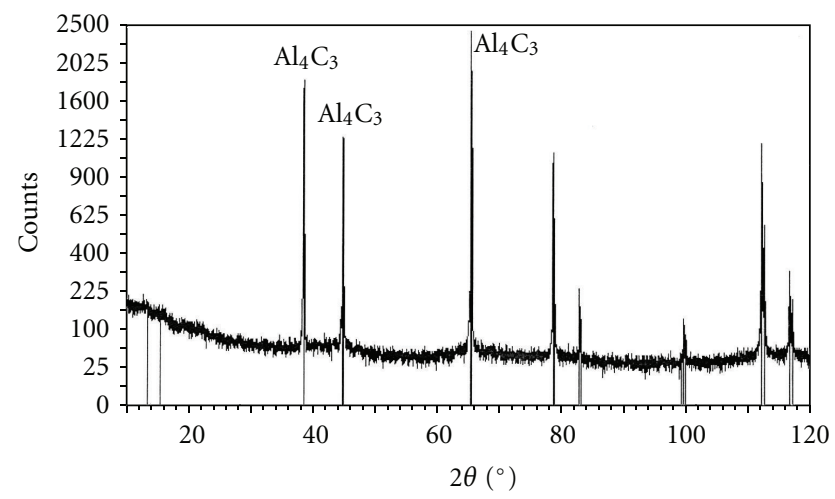

(b)

FIGURE 2: (a) XRD spectrum of sample 1. (b) XRD spectrum of sample 2 .

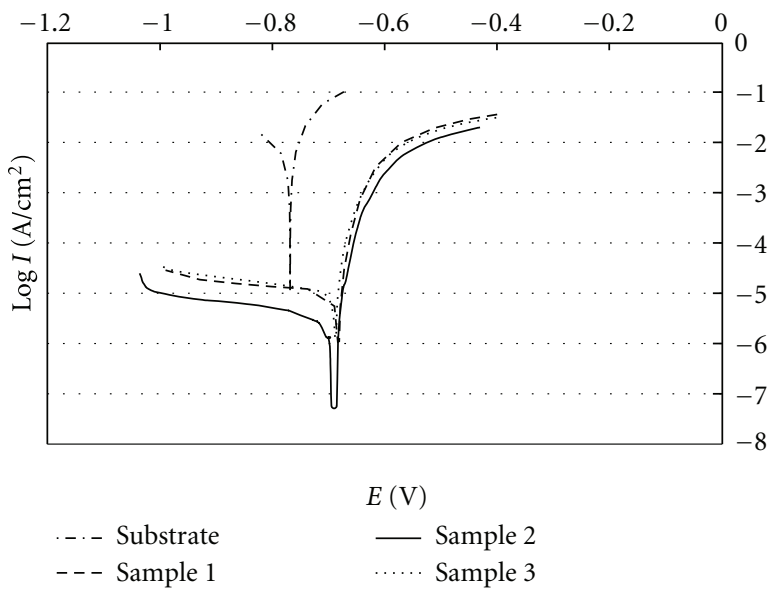

FIgURE 3: Chemical corrosion diagram.

intensity of the peak in radiation and finally $\theta$ is the angle of the peak. By applying this formula, the maximum precipitate grain size of carbide phase is about $57 \pm 5 \mathrm{~nm}$. The $\mathrm{Al}_{2} \mathrm{O}_{3}$ layer was not observed in the XRD pattern, because this layer was removed by sputtering process.

3.2. Chemical Corrosion Test. The corrosion properties of untreated and plasma-carburized samples were evaluated
TABLE 3: Electrochemical data of Al samples obtained from fit Tafel slopes.

\begin{tabular}{lcc}
\hline & $E_{\text {corr }}(\mathrm{V})$ & $I_{\text {corr }}\left(\mathrm{A} / \mathrm{cm}^{2}\right)$ \\
\hline Sample 1 & -0.681 & $1.62 \times 10^{-6}$ \\
Sample 2 & -0.691 & $1.012 \times 10^{-6}$ \\
Sample 3 & -0.685 & $2.519 \times 10^{-7}$ \\
Substrate & -0.707 & $5.5 \times 10^{-5}$ \\
\hline
\end{tabular}

$\mathrm{pt}$

TABLE 4: Case depth for different samples.

\begin{tabular}{lccc}
\hline Treated samples & Sample 1 & Sample 2 & Sample 3 \\
\hline Case depth $(\mu \mathrm{m})$ & 2.06 & 2.1 & 20.6 \\
\hline
\end{tabular}

using anodic polarization test in $3 \mathrm{~N} \mathrm{HCL}$ solution according to ASTM: G5-94. Table 3 lists the average values of the corrosion potential $\left(E_{\text {corr }}\right)$ and the passive current density $\left(i_{\text {Pass }}\right)$ for all the tested samples. Figure 3 indicates the potentiodynamic polarization of the samples.

According to Table 3, surface treatment causes that corrosion potential goes to positive values and is higher than untreated sample. The highest corrosion resistance was observed after plasma carburizing at highest time. Samples treated at lower temperature have a lower corrosion rate. However, sample 3 shows a lower corrosion rate compared to sample 2, which was plasma carburized at the same temperature but for a longer time.

3.3. SEM Analysis. Figure 4 shows SEM micrographs of surface morphology of aluminum samples after plasma carburizing at different temperatures and treatment times. In Figure 4(a), deep pitting corrosion is seen, but prolonged treatment resulted in general corrosion with no sign of pitting as shown in Figure 4(b). This can be attributed to the formation of a complete and dense modified layer that is achieved during long treatment times.

Figure 5 arises the SEM micrograph of cross-section. Each sample was cut by CNC machine and then was ground by SiC paper and prepared for SEM investigation. This layer is uneven which is due to the diffusing of carbon atom into aluminum grain. In all the samples, the modified layer appears after etching, as a single layer separated from the matrix by a strong etched line. Time has a great influence on the thickness of the carburized layer. This thickness increased dramatically from $2.1 \mu \mathrm{m}$ at 4 hours to $20.6 \mu \mathrm{m}$ at 8 hours.

Table 4 presents the thickness of each sample. It is also obtained from SEM figures, that the $\mathrm{Al}_{4} \mathrm{C}_{3}$ phase is a compact and continuous layer. The case depth is not controlled by diffusion.

\section{Conclusion}

Plasma carburizing of aluminum samples is performed in order to increase their corrosion resistance. Surface analysis of modified layer indicated that the layer growth increases with treatment time and temperature, but the parameter of 


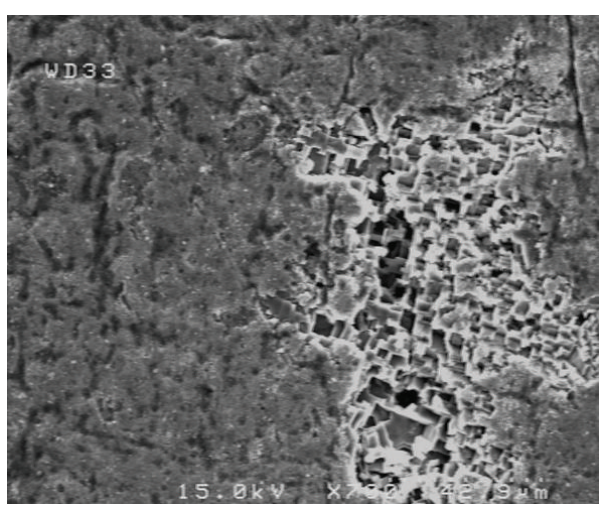

(a) SEM micrograph of sample 1

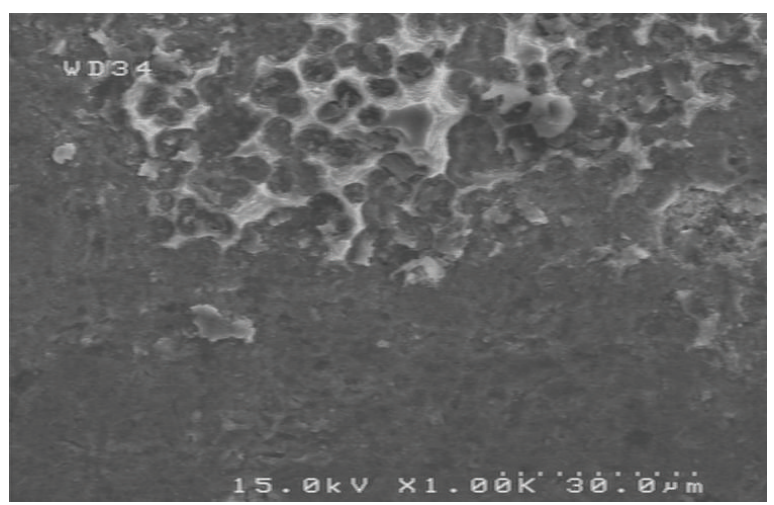

(b) SEM micrograph of sample 3

FIGURE 4: SEM micrographs of carburized Al 1100.

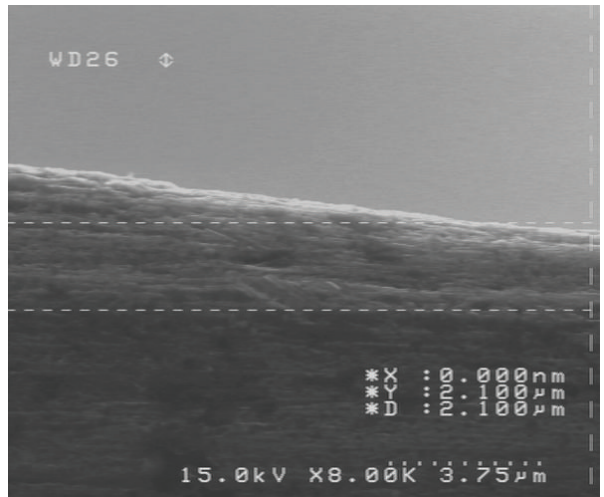

(a)

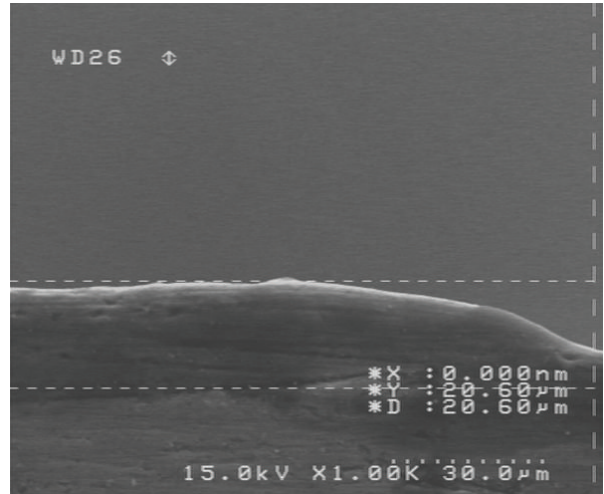

(b)

FIGURE 5: (a) SEM micrograph of cross-section of sample 2. (b) SEM micrograph of cross-section of sample 3.

time is more crucial than temperature. In fact, the complete surface layer with no defects is formed at higher carburizing time (8 hours), and temperature acts as a promoter. Results of corrosion tests also showed that corrosion behavior of samples depends on the quality of the modified layer, so that, the highest corrosion resistance with no effects of pitting or localized corrosion was achieved for samples treated at $700 \mathrm{~V}$, during $8 \mathrm{~h}$, and at 2 torr, pressure leads to the formation of $\mathrm{Al}_{4} \mathrm{C}_{3}$ layer with a thickness of $20.06 \mu \mathrm{m}$; the corrosion current is about $2.519 \times 10^{-7} \mathrm{~A} / \mathrm{cm}^{2}$. However, in the case of samples carburized for lower time, localized corrosion was seen at the weak points of the layer.

\section{References}

[1] J. R. Davis, Ed., Corrosion Of Aluminum And Aluminum Alloys, ASM International, 1999.

[2] M. F. Abd Rabbo, J. A. Richardson, and G. C. Wood, "A study of conversion coating development on aluminium in chromate/fluoride solutions using secondary ion mass spectrometry," Corrosion Science, vol. 18, no. 2, pp. 117-123, 1978.

[3] W. A. Badawy, M. M. Ibrahim, M. M. Abou-Romia, and M. S. El-Basiouny, "Kinetic studies on the dissolution behavior of anodic oxide films on aluminum in KF solutions," Corrosion, vol. 42, no. 6, pp. 324-328, 1986.
[4] G. Murtaza, S. S. Hussain, M. Sadiq, and M. Zakaullah, "Plasma focus assisted carburizing of aluminium," Thin Solid Films, vol. 517, no. 24, pp. 6777-6783, 2009.

[5] H. Arik and C. Bağci, "Investigation of influences of pressing pressure and sintering temperature on the mechanical properties of $\mathrm{Al}-\mathrm{Al}_{4} \mathrm{C}_{3}$ composite materials," Turkish Journal of Engineering and Environmental Sciences, vol. 27, no. 1, pp. 5358, 2003.

[6] P. S. Gilman and J. S. Benjamin, "Mechanical alloying," Annual Review of Materials Science, vol. 13, pp. 279-300, 1983.

[7] M. Moradshahi, T. Tavakoli, S. Amiri, and S. Shayeganmehr, "Plasma nitriding of Al alloys by DC glow discharge," Surface and Coatings Technology, vol. 201, no. 3-4, pp. 567-574, 2006.

[8] M. E. Rabanal, A. Várez, B. Levenfeld, and J. M. Torralba, "Magnetic properties of Mg-ferrite after milling process," Journal of Materials Processing Technology, vol. 143-144, no. 1, pp. 470-474, 2003. 

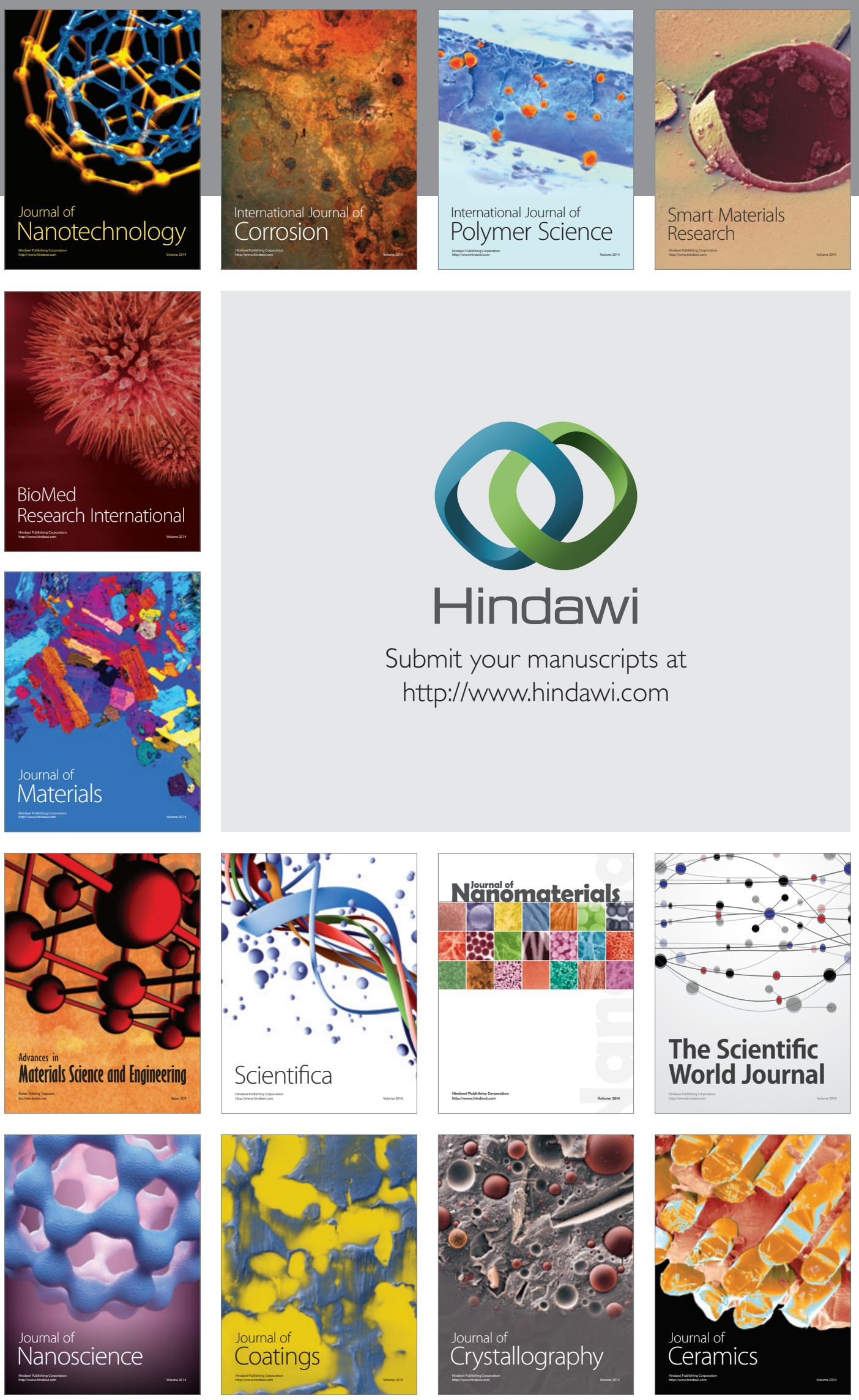

The Scientific World Journal

Submit your manuscripts at

http://www.hindawi.com

\section{World Journal}

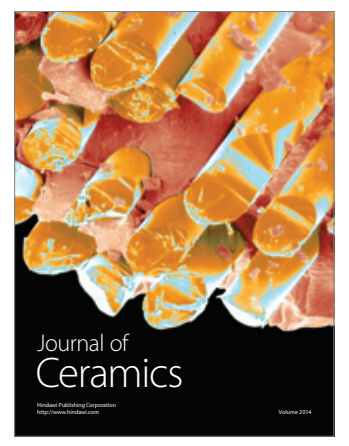

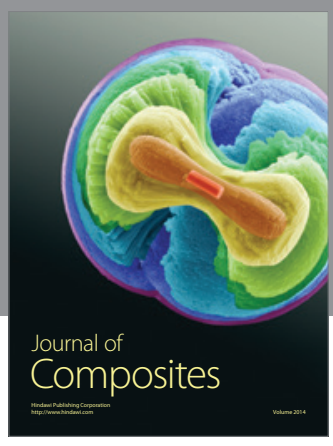
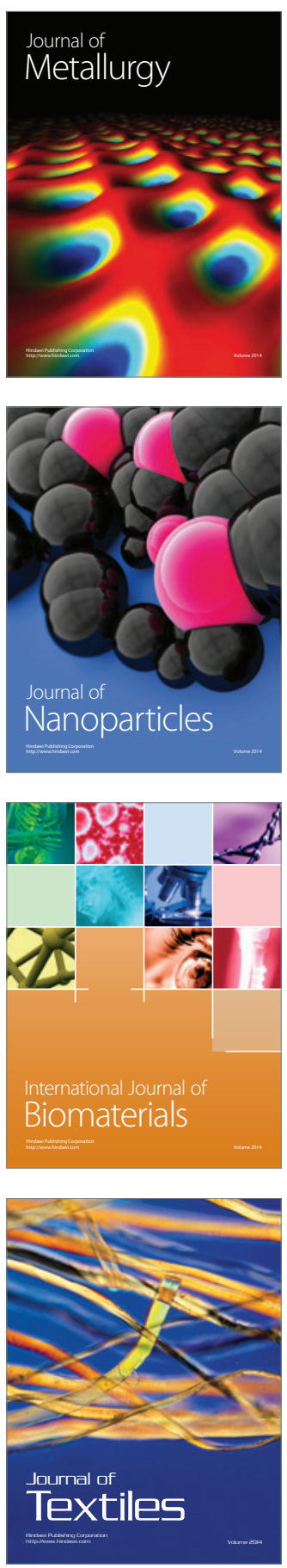